\title{
Las maestras y el ensayo como escritura cívica femenina en Repertorio Americano
}

\section{Women Teachers, Essays and Civic Writing in "Repertorio Americano"}

\author{
Marybel Soto Ramírez ${ }^{1}$ \\ Instituto de Estudios Latinoamericanos \\ Facultad de Filosofía y Letras \\ Universidad Nacional \\ Heredia, Costa Rica \\ msot@una.ac.cr
}

Recibido 17 de mayo de 2011 • Aceptado 26 de agosto de 2011

\begin{abstract}
Resumen. La escritura femenina, como todas las formas de producción simbólica desde las mujeres, ha existido y se ha desarrollado a pesar del mandato patriarcal de obedecer y callar que pesa sobre el género femenino. No es objetivo en esta reflexión, ahondar en las acciones y las obras de las mujeres transgresoras quienes, a lo largo de la historia y a pesar de, han ejercido esa forma de hacerse presente y afirmarse ante los otros que es la escritura. Mi propósito es identificar a las mujeres, quienes desde el oficio de maestras ejercitaron su escritura, combinaron su rol docente con el de escritoras y en la elaboración de sus discursos cívicos cuestionaron, precisamente, las concepciones de patriotismo y sentimiento cívico dentro del mismo proceso de construcción de una ciudadanía de la cual ellas no disfrutaban.
\end{abstract}

Palabras claves. Maestras-escritoras costarricenses, Repertorio Americano, civismo, discursos femeninos.

Abstract. Women writing, as any symbolic form of production, has existed and developed despite of the patriarchal imperative commanding women to obey and to remain silent. It is not the objective of this essay to deepen on the deeds and doings of those women who, throughout history and despite patriarchal mandates, have exerted their writing as a transgression as a way to show and to affirm themselves before others. Moreover, my purpose is to identify women in Repertorio Americano (1919-1958) who as teachers and writers elaborated civic discourses and questioned the very meaning of patriotism and civic feelings in the constructions of a citizenship they were not fully and formally entitled to.

Keywords. Costa Rican women teachers-writers, Repertorio Americano, civic feelings, female discourses.

\footnotetext{
Cuenta con una licenciatura en Estudios Latinoamericanos y una maestría en Estudios Latinoamericanos con énfasis en Cultura y Desarrollo, ambas por el Instituto de Estudios Latinoamericanos, IDELA, de la Universidad Nacional. Es Bachiller en Docencia por la misma Universidad, donde labora como académica e investigadora y es coordinadora el Programa Repertorio Americano del IDELA. Actualmente estudia su doctorado en Estudios Latinoamericanos con énfasis en Pensamiento Latinoamericano en dicha Universidad.
} 


\section{Transformación de la esfera de lo público: trabajo docente y escritura femenina}

Ya fuera como escritoras o como protectoras de las letras, las mujeres siempre han tenido una relación estrecha con la literatura. Baste recordar los salones de Las Preciosas y las poetisas del renacimiento para visibilizar su participación e importancia, no en su calidad de musas inspiradoras, sino como productoras de obras.

Sin embargo, como bien nos informa Ballesteros (1997), la cultura ha sido terreno reservado a los hombres y, en aquella época, eran escasas las mujeres que tenían acceso a ese círculo letrado.

Entre varias causas, esta aseveración puede entenderse, por un lado, en la sempiterna pobreza con que Virginia Woolf caracteriza a las mujeres en general, en tanto que históricamente se les ha negado disponer de patrimonio en vista que este era administrado por el varón, declarado con poder sobre lo femenino desde el pater familia. Por el otro, puede comprenderse, desde las perversas razones esgrimidas para mantener a las mujeres en la pobreza ya no material sino de espíritu que es la ignorancia: el patriarcado negó a las mujeres el acceso a la educación convirtiendo esta en un barniz de adorno a las dotes personales femeninas o a lo sumo, en un instrumento para medio sobrevivir decentemente en el mundo, cuando no se contara con la suerte del amparo masculino.

Será por ello, como bien establece Prada (2001), que el primer derecho por el que lucharon las mujeres, incluso antes del sufragio, fue por el de la educación. En Nuestra América, en el siglo XIX, el pensamiento de las luces consideró necesaria y apropiada la educación femenina con un objetivo preciso: enseñar a amar a la patria. En este amor a la patria se manifestaría, como aspecto vital, la formación de los ciudadanos que descansaba en la madre como primer pilar de socialización.

Aunque desde mediados del siglo XIX ya se contaba con impresos con producción y no pocas veces con dirección femenina en ellos, como O Journal do Senoras, en Brasil en 1852, dirigido por Juana Manso, o Violetas de Anahuac, de 1882 dirigido por Laureana Wright González en México, no es sino con el paso hacia el siglo XX cuando surgieron, con gran fuerza, escritos de mujeres recogidos, casi siempre, en revistas culturales y otras de alcance decididamente más político.

Encontramos así a mujeres que hoy se identifican como consagradas de las letras latinoamericanas por su participación en emprendimientos editoriales, el periodismo y la literatura, entre ellas, Clorinda Matto de Turner, en Perú; Juana Manuela Gorriti, en Argentina; Juana Belén Gutiérrez, en México, quienes rebelaron, junto con su influjo creador potente, demandas sistemáticas por la educación científica de las mujeres, que despejara del clima generalizado de ignorancia femenina.

Yo considero que, en Costa Rica, la relación entre acceso a la educación de las mujeres, formación docente y ejercicio escritural se conjugó en la conformación de un sujeto social y político específico, con indicios de una nueva identidad intelectual femenina que afirma y legitima su participación social y pública en los asuntos del país y del continente. Esta nueva identidad femenina intelectual se expresará de manera particular en las maestras.

Las maestras, más allá de su importancia en la puesta en marcha de programas didácticos, lograron, con su participación, acción y pensamiento, en la Costa Rica de inicios del siglo XX, una incidencia social y política que cambiaría el país. Las maestras participaron en la implementación de políticas educativas novedosas, en programas sociales a favor de la infancia y en la beneficencia pública, pero también ejercitaron su presencia en centros de cultura, en los foros de discusión, en la prensa y en las revistas culturales de la época. 
En el escenario político costarricense, estas mujeres educadoras se constituyeron en 1919, como apunta el investigador Molina, “(...) en vanguardia del movimiento cívico que derrocó al régimen de los Tinoco" (2003, p. 70).

En esta larga lucha librada por mujeres y algunos varones visionarios a favor del acceso femenino a la formación y a la cultura, el ingreso a las escuelas normales fue la puerta de entrada a la educación superior y es, a mi juicio, un pequeño y a la vez gran peldaño mediante el cual se logró que el llamado, condescendientemente, bello sexo, creciera intelectualmente. A pesar de que el trabajo de educar fuera conceptualizado como extensión natural de las tareas de la madre, como lo consideraba (Sarmiento, 1939), y como algo que residía en el instinto de característica femenil, el requisito de "habilitar a su sexo para el preceptorado", le daría "industria honrosa" a las mujeres (La educación de las mujeres y su influencia, párr. 4).

Sin embargo, como indica Prada (2001), los patriarcas no consideraron que, con el acceso a la instrucción, las mujeres obtenían una llave para abrir la caja de Pandora, que la formación y que el ejercicio magisterial femenino se constituiría en “(...) un escenario de profundos y complejos procesos de cambio en cuyo curso (...) las mujeres lograron una posición sin precedentes en la esfera pública (...) (Molina, 2003, xii).

Con la presencia de las mujeres en la esfera de lo público en su calidad de maestras de escuela, el mismo sistema les concedió autoridad para la expresión y la formación de opinión. En la formación del ciudadano bueno, respetuoso del Estado liberal, defensor de la patria, las mujeres empezaron a construir ciudadanía: derecho que formalmente permaneció vedado para ellas hasta 1949.

El binomio magisterio escritura se constituyó indisolublemente, con la característica particular de que, en adelante, esa escritura no sería solamente literaria, sino también política.

\section{Las mujeres y el universo de las revistas culturales: maestras escritoras en Repertorio Americano}

Devés-Valdés (2007) ha identificado, en sus investigaciones, que Repertorio Americano fungió como la principal de las redes intelectuales americanas en la primera mitad del siglo XX. Publicado ininterrumpidamente de 1919 a 1958, por el maestro e intelectual costarricense Joaquín García Monge, Repertorio Americano es un referente obligado del pensamiento y la cultura latinoamericana.

Por ello es de capital importancia corroborar que gran cantidad de mujeres escribió en esta Revista que, desde Costa Rica, se proyectó a todo el Continente. La antropóloga feminista May Brenes (2004), en su investigación de posgrado, identificó 103 textos de mujeres costarricenses y 414 de mujeres latinoamericanas, canadienses y estadounidenses en dicha Revista.

Para el presente trabajo se contempló, únicamente, los escritos de maestras costarricenses ${ }^{2}$ para analizar cuáles eran sus planteamientos sobre lo cívico. Se debe entender el término cívico desde su raíz latina civis en la definición de María Moliner: "comportamiento propio de un buen ciudadano" (1997, p. 639), en tanto cívico, en el campo léxico-semántico de mi universo de estudio, contiene un sema que refiere a compromiso patriótico, individual y personal, del que carece civilidad.

\footnotetext{
No se tomó en cuenta, sin embargo, los escritos de Carmen Lyra ni de Luisa González, pues el interés estribaba en identificar qué otras maestras costarricenses habían escrito en Repertorio Americano.
} 
A pesar de que la instrucción cívica en Costa Rica se planteó como “(...) las nociones cardinales que dominan nuestro derecho público (...)” como “(...) medio eficaz de que se logre la adaptación de los caracteres a la forma republicana, la cual exige de todos los miembros del Estado ser células conscientes del cuerpo político (...)" para que sepan “(...) cuál es el mecanismo administrativo, cómo funciona la máquina de gobierno (...)” y “ (...) qué deberes lleva consigo la ciudadanía” (Jiménez, 1926, pp. 3-4), la instrucción cívica estuvo unida estrechamente con nociones de moral, como obligación escolar de “ (...) todo niño residente en República, sano, (...) de los 8 a los 14 años” (p. 111).

Las instituciones escolares se consideraron un mecanismo idóneo para forjar la conciencia cívica y, por ende, para preparar para el ejercicio de la ciudadanía. Es el mismo Presidente Alfredo González Flores, quien declararía la instrucción como “(...) base de la República y condición indispensable de la ciudadanía” (González, 1979, p. 351),

Palacios (2006) apunta que, de 1888 hasta 1920, los programas de educación cívica y moral se dedicaron a justificar y reproducir contenidos al interno de la sociedad de diferenciación dicotómica y jerarquizada entre lo masculino y lo femenino. A pesar de ello, muchas maestras asumieron para sí una conciencia cívica diferente y se atrevieron a divulgarla en sus escritos.

Esta conciencia cívica partió del conocimiento de primera mano de estas maestras, constituido a partir de la realidad cotidiana que vivían ellas mismas, en su interacción con la situación de la niñez que atendían, en el conocimiento de las condiciones sociales de las familias, y también, en la formación que, a través de la lectura, iban construyendo, a partir de mantenerse informadas de lo que sucedía en otras latitudes. Las mujeres del magisterio fueron mujeres intelectuales. Y como intelectuales, asumieron un compromiso con la llamada cuestión social.

La proximidad de las maestras al conocimiento de la realidad y su legitimación social a partir de su profesión facilitó que un discurso femenino cívico se filtrase con poca sospecha, enarbolando posturas que incluían llamados de resistencia; de lucha contra el imperialismo y contra la corrupción; a favor de la defensa de la soberanía; posiciones en pro del americanismo y de la unidad hispanoamericana; el clamor por el progreso de la patria entendido como el de todos los ciudadanos, mujeres incluidas, mediante el mejoramiento de las condiciones sociales de las mayorías, con especial énfasis en la protección a la infancia y a las madres obreras.

Si bien la escritura femenina se expresa en géneros diversos, en la historia de las ideas ha cobrado importancia capital para la arqueología y la genealogía del pensamiento femenino el expresado mediante el género epistolar y el ensayístico.

Como acota Weinberg (2004), el ensayo refiere constantemente a un punto de vista y, por tanto, es el género donde de manera más clara se puede rastrear ese estar y ser en el mundo de un autor o autora. No es extraño que la epístola y el ensayo hayan sido usados tan profusamente por las maestras. Ambas son formas de una escritura de sí, de estilo más bien libre, si se compara con otros géneros mayores y que busca mover a la audiencia a una posición determinada del autor, que llama a tomar posición y analiza los hechos de bona-fide, y no solo como medio de persuasión.

Tanto en el ensayo como en la epístola, creación e intención se combinan para lograr "una expresión del pensamiento", como expone Weinberg (2004, p. 8), que es rastreable en las revistas culturales de época.

Tratar de lograr una ubicación de esta escritura femenina en el universo de escritos publicados en la revista Repertorio Americano como fuente primaria de investigación fue una tarea difícil por la heterogeneidad general de colaboraciones que declara el mismo nombre de la publicación. 
La variedad en los tipos de escrito según identificación del género literario se puede observar en la siguiente tabla:

Tabla 1

Cantidad de escritos y tipos identificados

\begin{tabular}{|c|c|c|c|c|c|c|c|c|c|c|}
\hline 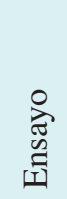 & $\begin{array}{l}8 \\
80 \\
0 \\
0 \\
0 \\
\frac{0}{4}\end{array}$ & 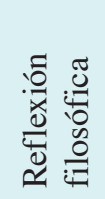 & 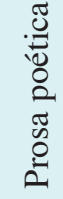 & 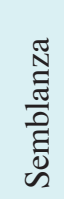 & 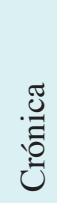 & 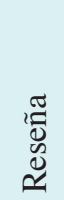 & 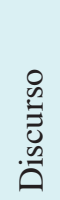 & 穿 & $\frac{\stackrel{0}{\frac{\pi}{2}}}{\underline{\underline{v}}}$ & 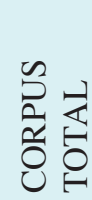 \\
\hline 30 & 2 & 1 & 7 & 1 & 1 & 2 & 1 & 3 & 1 & 50 \\
\hline
\end{tabular}

Nota. Elaboración propia a partir de Repertorio Americano 1919-1959.

Desde mi punto de vista, las páginas del Repertorio Americano estuvieron abiertas a las letras femeninas y en particular a la producción de las maestras escritoras costarricenses, lo cual es evidente en la variedad de escritos y en la cantidad de ensayos publicados a ellas.

Es valioso considerar que, a pesar de que en el imaginario nacional la imagen de la maestra se construyó fuertemente asociado al de la madre, la obra de las mujeres del magisterio de la primera mitad del siglo XX en Costa Rica está más allá de la maternalidad y la abnegación mariana con que la definía la sociedad androcéntrica definía a las mujeres.

Ellas, como fue característico en las maestras latinoamericanas, establecieron prácticas discursivas en la formación de opinión pública y, por tanto, asumieron una actitud propositiva que, sin embargo, ha pasado marginada en la investigación historiográfica nacional, hasta recientemente.

En vista de que los intereses de investigación personales como los actos de escritura no son absolutamente neutrales, declaro mi posición de trabajo afín con el feminismo como postura epistemológica y, por tanto, mi interés por los textos que den cuenta de los avances y las luchas del movimiento de mujeres y, por ello, me sitúo también como una participante del discurso para analizar el "tránsito por el espacio público" (Ungo, en Gargallo, 2004, p. 97) de las maestras costarricenses en esta época e identificar las condiciones específicas de estas en sus posibilidades de acción.

El estudio de la producción escrita de las maestras de la primera mitad del siglo XX y su relación con las revistas culturales es una veta de investigación abierta a quienes quieran adentrarse a indagar sobre cómo las mujeres del magisterio contribuyeron en la conformación del pensamiento político costarricense y latinoamericano.

\section{Las maestras y la expresión cívica: Géneros y discursos}

El discurso cívico de la primera mitad del siglo XX en Costa Rica buscaba la formación de ciudadanos leales a su Patria a través del sentimiento de amor hacia ella, para que fueran personas útiles a la sociedad, entendiendo esta utilidad como virtud cívica: la sociedad se bosquejaba desde el proyecto político de la clase dominante. 
La idea de construcción de este tipo ciudadano se ampliaba a la concepción de una colectividad que era, sin embargo, excluyente de las mujeres, en tanto que el ciudadano era varón, alfabetizado, instruido en los deberes y derechos para con la patria, que se identificado con un cierto ideario político promovido por las clases dominantes. En el imaginario de este colectivo, confluyen idiosincrasia e identidad, las cuales se manifiestan mediante el sentido de pertenencia a esa patria con características específicas de lo costarricense.

Los diarios y revistas dan cuenta de la visión cívica que se construía en esa época. Son fuentes para la investigación académica que presupone un verdadero trabajo de arqueología en la búsqueda e identificación de artículos, autorías y relaciones personales, sociales, intelectuales que se construían alrededor de los impresos. Repertorio Americano no fue una excepción. Aunque ha sido entendido como la obra de toda una vida y el resultado titánico de la labor editorial del intelectual y escritor Joaquín García Monge, también sus páginas, si se las interroga, ofrecen respuestas interesantes y novedosas. La participación femenina de maestras en la creación de opinión es una de ellas.

En Repertorio Americano se identificó un total de 50 escritos de ocho maestras, como se resume en el siguiente cuadro:

Tabla 2

Identificación de maestras y cantidad de escritos

\begin{tabular}{|c|c|c|c|c|c|c|c|c|}
\hline 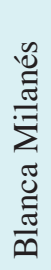 & 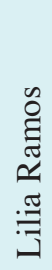 & 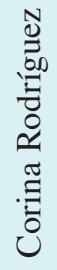 & 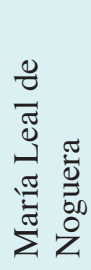 & $\begin{array}{l}0 \\
\frac{0}{0} \\
\frac{0}{0} \\
1 \\
\frac{\pi}{0} \\
\frac{\pi}{0}\end{array}$ & 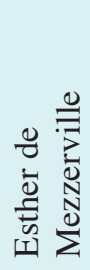 & 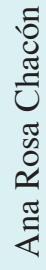 & 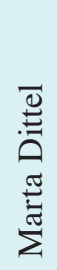 & 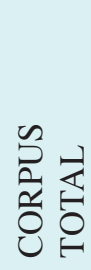 \\
\hline 20 & 10 & 8 & 7 & 1 & 1 & 2 & 1 & 50 \\
\hline
\end{tabular}

Nota: Elaboración propia a partir de Repertorio Americano (1919-1958).

$\mathrm{Al}$ enfocarse en el ensayo, en tanto este género es literatura de ideas, la relación de escritos por autora que se logró despejar es el siguiente:

Tabla 3

Relación de escritos por maestra en la construcción del corpus

\begin{tabular}{|c|c|}
\hline Maestra & Ensayos publicados \\
\hline Blanca Milanés & 13 ensayos \\
\hline Lilia Ramos Valverde & 8 ensayos \\
\hline Corina Rodríguez López & 6 ensayos \\
\hline María Leal de Noguera & 2 ensayos \\
\hline Esther de Mezzerville & 1 ensayo \\
\hline CORPUS TOTAL & 30 ensayos \\
\hline
\end{tabular}

Nota: Elaboración propia 
La escritura de estas maestras se evidencia muy cuidada en el uso del lenguaje, sencilla, directa, bella y poética. Su ensayismo se ejercita, como asienta (Weinberg, 2004), no solo en la forma como queda redactado algo, sino en las ciertas condiciones con las que ese ejercicio, que es el experimentar con las palabras, pensamientos e intención, queda indirectamente plasmado en epístolas, en aforismos o apólogos y, además de ello, contener la capacidad y la cualidad profundamente ensayística que encierra preguntarse por un tema, abordarlo desde distintos ángulos y reflexionar sobre él. Esta serie de elementos que identifican un ejercicio escritural y un producto, desde lo ensayístico y desde lo femenino, se plasma como una escritura de sí.

La tabla que a continuación se ofrece, presenta una identificación de las maestras con mayor publicación de trabajos en Repertorio Americano de 1919 a 1959, por autora; se incluye, asimismo, la referencia dentro del universo de la Revista, la temática y el género literario a que pertenece la colaboración.

Tabla 4

Colaboraciones de maestras costarricenses en Repertorio Americano, 1919-1958, por autora y título

Blanca Milanés (seud. de Carlota Brenes Arguello. 1905-1986)

\begin{tabular}{|c|c|c|c|}
\hline Título & Referencia & Temática & Género literario \\
\hline Trébol teológico & $\begin{array}{l}\text { Repertorio Americano, XXII, No } 16 \\
(2-5-1931) \text { pp. } 258-259\end{array}$ & $\begin{array}{l}\text { Las virtudes fraternales de la fe, } \\
\text { la esperanza y la caridad }\end{array}$ & Ensayo \\
\hline Un artista costarricense & $\begin{array}{l}\text { R. A. XX, No. } 12 \text {, } \\
(22-3-1930) \text { p. } 182\end{array}$ & $\begin{array}{l}\text { Noé Solano, un artista del dibujo. } \\
\text { Crítica a la prensa aduladora del } \\
\text { artista mediocre. }\end{array}$ & Ensayo \\
\hline Acerca del valor civil & $\begin{array}{l}\text { Repertorio Americano, XX, } N^{\circ} 12 \text {, } \\
(24-5-1930) \text { pp. } 312 \text { y } 314\end{array}$ & $\begin{array}{l}\text { Valor civil es igual a justicia. } \\
\text { Análisis político de la situación } \\
\text { del país. Maestros que han } \\
\text { sido ejemplo de valor civil. Las } \\
\text { maestras en } 1919 \text { dieron ejemplo } \\
\text { de valor civil. }\end{array}$ & Ensayo \\
\hline Todo un hombre & $\begin{array}{l}\text { Repertorio Americano, XIX, Nº } 20 \\
(23-11-1929), \text { p. } 320\end{array}$ & $\begin{array}{l}\text { Ante muerte de Omar Dengo, } \\
\text { más preclaro intelectual del } \\
\text { país, lo califica como apóstol } \\
\text { de virtud: voluntad, talento y } \\
\text { bondad }\end{array}$ & Ensayo \\
\hline Bestezuelas de Dios & $\begin{array}{l}\text { Repertorio Americano, XIX, N }{ }^{\circ} 4 \\
(27-7-1929) \text { p. } 60\end{array}$ & $\begin{array}{l}\text { Análisis sobre el escarabajo } \\
\text { y el comején. Relaciona } \\
\text { características de estos animales } \\
\text { con actitudes de algunas } \\
\text { personas }\end{array}$ & Ensayo \\
\hline La raíz y el gusano & $\begin{array}{l}\text { Repertorio Americano, XIII, Nº } 12 \\
\text { (25-9-1926), pp. 191-192 }\end{array}$ & $\begin{array}{l}\text { El imperialismo de Estados } \\
\text { Unidos, apología de los gusanos/ } \\
\text { individuos que se ufanan y } \\
\text { buscan molestar las raíces/ } \\
\text { valores }\end{array}$ & Apólogo \\
\hline
\end{tabular}




\section{URL: http://www.una.ac.cr/educare}

\begin{tabular}{|c|c|c|c|}
\hline Título & Referencia & Temática & Género literario \\
\hline Las torres del inalámbrico & $\begin{array}{l}\text { Repertorio Americano, XIII, No } 5 \text {, } \\
(7-7-1926) \text {, p. } 80\end{array}$ & $\begin{array}{l}\text { Crítica del egoísmo en el } \\
\text { conocimiento en comparación } \\
\text { con dos torres que sirven para } \\
\text { difundir ideas (radio) }\end{array}$ & $\begin{array}{l}\text { Reflexión } \\
\text { filosófica }\end{array}$ \\
\hline Saña y candor & $\begin{array}{l}\text { Repertorio Americano, XII, } N^{\circ} 15 \text {, } \\
(17-7-1926), \text { p. } 232\end{array}$ & $\begin{array}{l}\text { Habrá mejores tiempos donde } \\
\text { la bondad y la justicia rijan el } \\
\text { mundo. }\end{array}$ & Ensayo \\
\hline La cisterna & $\begin{array}{l}\text { R. A. XII, No } 8 \\
(22-2-1926), \text { p. } 119\end{array}$ & $\begin{array}{l}\text { Relación entre un pozo de } \\
\text { agua profundo y la soledad del } \\
\text { corazón sin esperanza }\end{array}$ & Ensayo \\
\hline El hombre y el perro & $\begin{array}{l}\text { Repertorio Americano, XI, } N^{\circ} 8 \\
(21-12-1925), \text { p. } 239\end{array}$ & $\begin{array}{l}\text { Ante la crueldad humana teme } \\
\text { que el hombre no sea imagen y } \\
\text { semejanza de Dios }\end{array}$ & Ensayo \\
\hline Los dos pinos & $\begin{array}{l}\text { Repertorio Americano, } X, N^{\circ} 17 \text {, } \\
\text { (6-7-1925) p. } 268\end{array}$ & $\begin{array}{l}\text { La depredación del hombre sobre } \\
\text { la naturaleza }\end{array}$ & Apólogo \\
\hline El trovador de la dulzaina & $\begin{array}{l}\text { Repertorio Americano, } X, N^{\circ} 9, \\
(4-5-1925), \text { p. } 130\end{array}$ & $\begin{array}{l}\text { El sentimiento infantil ante la } \\
\text { indiferencia pública y la injusticia }\end{array}$ & Ensayo \\
\hline $\begin{array}{l}\text { La araña } \\
\text { Las montañas } \\
\text { "La hora que pasa" }\end{array}$ & $\begin{array}{l}\text { Repertorio Americano, IX, } \mathrm{N}^{\circ} 11 \text {, } \\
(17-11,1924) \text { p. } 172\end{array}$ & $\begin{array}{l}\text { La tragedia del campesino } \\
\text { que pierde su cosecha en los } \\
\text { temporales y la paciencia como } \\
\text { forma de sobrellevar la pena. } \\
\text { La brevedad de la existencia } \\
\text { humana }\end{array}$ & Ensayo \\
\hline El pozo seco & $\begin{array}{l}\text { Repertorio Americano, IX, } N^{\circ} 19 \text {, } \\
(19-1-1925), \text { p. } 301\end{array}$ & $\begin{array}{l}\text { La sequedad del pozo es como la } \\
\text { sequedad del alma sin amor }\end{array}$ & Ensayo \\
\hline $\begin{array}{l}\text { El grillo cantor } \\
\text { Vaso de amor } \\
\text { Música celeste } \\
\text { Gota de rocío } \\
\text { "La hora que pasa" }\end{array}$ & $\begin{array}{l}\text { Repertorio Americano, VIII, } N^{\circ} 15 \\
(30-6-1924), \text { p. } 231\end{array}$ & $\begin{array}{l}\text { El privilegio de la libertad } \\
\text { Amor que llena el alma } \\
\text { La pequeñez humana en } \\
\text { comparación con la inmensidad } \\
\text { del firmamento } \\
\text { Trascendencia por el Amor }\end{array}$ & Prosa poética \\
\hline El recreo & $\begin{array}{l}\text { Repertorio Americano, IX, } \mathrm{N}^{\circ} 19 \text {, } \\
(19-1-1925), \text { p. } 302\end{array}$ & $\begin{array}{l}\text { La injusticia de la pobreza } \\
\text { mostrada durante el recreo de } \\
\text { las niñas y cómo esa podría ser } \\
\text { causa de prostitución a futuro. } \\
\text { Un magisterio viciado por las } \\
\text { perjuras personales y maestras } \\
\text { insensibles ante la necesidad de } \\
\text { sus niñas. }\end{array}$ & Ensayo \\
\hline $\begin{array}{l}\text { Las primeras lluvias } \\
\text { La guacamaya } \\
\text { Florecillas } \\
\text { Esas nubes } \\
\text { "La hora que pasa" }\end{array}$ & $\begin{array}{l}\text { Repertorio Americano, VIII, } N^{\circ} 8 \text {, } \\
(12-5-1924), \text { p. } 127\end{array}$ & $\begin{array}{l}\text { Lluvias de abril. } \\
\text { La gazmoñería y el egoísmo en } \\
\text { el ser humano. } \\
\text { La humildad bella de las flores } \\
\text { silvestres hace pensar en que se } \\
\text { confunde sencillez con tontería } \\
\text { Anhelo del alma por la libertad } \\
\text { de las nubes }\end{array}$ & Prosa poética \\
\hline
\end{tabular}


María Leal de Noguera (1892-1989)

\begin{tabular}{|c|c|c|c|}
\hline Título & Referencia & Temática & Género literario \\
\hline $\begin{array}{l}\text { De la vida en la costa } \\
\text { (Dedicado a Emma } \\
\text { Gamboa) }\end{array}$ & $\begin{array}{l}\text { Repertorio Americano, V, } N^{\circ} 4 \\
(5-5-1955) \text { p. } 55\end{array}$ & $\begin{array}{l}\text { La cruel agresión de un padre a } \\
\text { su hija como castigo, el papel del } \\
\text { "Resguardo" y la autoridad del } \\
\text { juez y el médico y la actitud de } \\
\text { perdón de la hija al padre }\end{array}$ & Relato \\
\hline El indio y el español & $\begin{array}{l}\text { Repertorio Americano, XLVII, No } 8 \text {, } \\
\text { (15-7-1951) p. } 1252\end{array}$ & $\begin{array}{l}\text { Un español busca aprovecharse } \\
\text { del alimento de un indio }\end{array}$ & Cuento \\
\hline $\begin{array}{l}\text { Bienvenido } \\
\text { (remitido por la autora a los } \\
\text { niños de EUA a través de } \\
\text { Doris Stone) }\end{array}$ & $\begin{array}{l}\text { Repertorio Americano, XLV, } N^{\circ} 17 \text {, } \\
(20-7-1949) \text { pp. } 267,268\end{array}$ & $\begin{array}{l}\text { La pobreza del campesino, hijos } \\
\text { numerosos, abandono de infantil. } \\
\text { Un huérfano que después de } \\
\text { mucho sufrir llega a rey y lleva } \\
\text { a su familia adoptiva a vivir con } \\
\text { él. }\end{array}$ & Cuento \\
\hline Pejecito, peje sapo & $\begin{array}{l}\text { Repertorio Americano, XLIII, N }{ }^{\circ} 3 \\
(26-7-1947), \text { pp. } 49 \text { a } 51\end{array}$ & $\begin{array}{l}\text { Las vicisitudes de un pescador } \\
\text { generoso por salvar a su esposa. } \\
\text { Comenta la autora cómo nació la } \\
\text { historia y la dedica a los niños } \\
\text { de América }\end{array}$ & Cuento \\
\hline Cómo nació un ideal & $\begin{array}{l}\text { Repertorio Americano, XL, N } 18 \\
(13-11-1946), \text { pp. } 191-192\end{array}$ & $\begin{array}{l}\text { Su ideal es la promesa de un } \\
\text { alma buena, limpia, humilde y } \\
\text { un corazón virtuoso }\end{array}$ & Ensayo \\
\hline Respuesta & $\begin{array}{l}\text { Repertorio Americano, XXXVIII, N } \\
\text { 16, (13-11-1941), p. } 253\end{array}$ & $\begin{array}{l}\text { Respuesta a un cuestionario } \\
\text { realizado por Emma Gamboa } \\
\text { sobre cómo empezó a escribir } \\
\text { literatura infantil. Apunta a la } \\
\text { falta de esta en Guanacaste, la } \\
\text { importancia del matiz regional } \\
\text { como valor pedagógico y la } \\
\text { importancia del cuento como } \\
\text { herramienta metodológica para } \\
\text { los maestros. }\end{array}$ & Ensayo \\
\hline
\end{tabular}




\section{URL: http://www.una.ac.cr/educare}

Lilia Ramos Valverde (1903-1988)

\begin{tabular}{|c|c|c|c|}
\hline Título & Referencia & Temática & Género literario \\
\hline $\begin{array}{l}\text { Sin noviciado Yolanda } \\
\text { Oreamuno escribe obra } \\
\text { psicoanalítica }\end{array}$ & $\begin{array}{l}\text { Repertorio Americano, XLVI, } N^{\circ} 12 \\
(20-6-1950) \text { pp. } 185 \text { a } 188\end{array}$ & $\begin{array}{l}\text { Las grandeza literaria de } \\
\text { Yolanda Oreamuno ante la } \\
\text { envidia y la ignorancia gazmoña } \\
\text { de sus coterráneos. Análisis de } \\
\text { la obra de Oreamuno desde el } \\
\text { psicoanálisis }\end{array}$ & Ensayo \\
\hline $\begin{array}{l}\text { Silueta de Nina Bull } \\
\text { (incluye traducción del } \\
\text { artículo de la insigne } \\
\text { psicóloga) }\end{array}$ & $\begin{array}{l}\text { Repertorio Americano, XLIV, } N^{\circ} 17 \text {, } \\
(20-12-1948) \text { p. } 258\end{array}$ & $\begin{array}{l}\text { Presenta a la psicóloga } \\
\text { estadounidense y su trabajo. La } \\
\text { califica de hispanista. }\end{array}$ & Reseña. \\
\hline Xochimilco & $\begin{array}{l}\text { Repertorio Americano, XLI, N }{ }^{\circ} 15 \text {, } \\
(12-11-1945) \text { p. } 240\end{array}$ & $\begin{array}{l}\text { Retrato de la belleza y tradición } \\
\text { en Xochimilco }\end{array}$ & Ensayo \\
\hline Alfredo Cardona Peña & $\begin{array}{l}\text { Repertorio Americano, XLI, } N^{\circ} 15 \\
(12-11-1945), \text { p. } 240\end{array}$ & $\begin{array}{l}\text { Semblanza del escritor cuando } \\
\text { era joven. Resalta su versatilidad, } \\
\text { su estudio, su esfuerzo por } \\
\text { insertarse en la sociedad } \\
\text { mexicana, su disposición para } \\
\text { educar }\end{array}$ & Ensayo \\
\hline $\begin{array}{l}\text { Al margen de una carta } \\
\text { reveladora } \\
\text { "Qué hora es?" }\end{array}$ & $\begin{array}{l}\text { Repertorio Americano, XL, N }{ }^{\circ} 7 \\
(10-4-1943) \text { pp. } 110-111\end{array}$ & $\begin{array}{l}\text { Lecturas para maestros. Análisis } \\
\text { psicológico de la obra kafkiana } \\
\text { y de la carta que escribe Kafka } \\
\text { a su padre. Consejos a los } \\
\text { maestros en el trato con los } \\
\text { niños. Educarse para educar. El } \\
\text { trabajo del educador es sagrado. }\end{array}$ & Ensayo \\
\hline $\begin{array}{l}\text { Tizas de colores, el libro de } \\
\text { la educación }\end{array}$ & $\begin{array}{l}\text { Repertorio Americano, XXVI, N } 20 \\
(27-5-1933), \text { p. } 317\end{array}$ & $\begin{array}{l}\text { Reseña del libro de la maestra } \\
\text { argentina Herminia C. Brumana. } \\
\text { Critica que el maestro esté } \\
\text { impedido de enseñar ciudadanía } \\
\text { y política so pena de ser } \\
\text { destituido y procesado por } \\
\text { sedición. }\end{array}$ & Reseña \\
\hline $\begin{array}{l}\text { Balanza de palabras y } \\
\text { hombres }\end{array}$ & $\begin{array}{l}\text { Repertorio Americano, XXVI, No } 8 \text {, } \\
(27-7-1932), \text { p. } 48\end{array}$ & $\begin{array}{l}\text { Intelectuales comprometidos } \\
\text { con la justicia que sufren } \\
\text { persecución. Analiza el } \\
\text { discurso oficial que sanciona } \\
\text { las cualidades de los buenos } \\
\text { ciudadanos }\end{array}$ & Ensayo \\
\hline
\end{tabular}


URL: http://www.una.ac.cr/educare

\begin{tabular}{|l|l|l|l|}
\hline Título & Referencia & Temática & Género literario \\
\hline $\begin{array}{l}\text { Siempre recordaremos a } \\
\text { don Arturo Urién }\end{array}$ & $\begin{array}{l}\text { Repertorio Americano, XXV, No3, } \\
\text { (23-7-1932) p. 48 }\end{array}$ & $\begin{array}{l}\text { En ocasión de nombrar un } \\
\text { kindergarten en honor del } \\
\text { diplomático argentino, benefactor } \\
\text { de la escuela de Carmen Lyra. } \\
\text { Ayudó a construir bibliotecas, } \\
\text { botiquines y dar zapatos a los } \\
\text { niños costarricenses. Se nombró } \\
\text { un kindergarten en su honor. }\end{array}$ & Ensayo \\
\hline $\begin{array}{l}\text { Un revolucionario del } \\
\text { Medioevo }\end{array}$ & $\begin{array}{l}\text { Repertorio Americano, XXIV, No 15, } \\
(30-4-1932), \text { p. 128 }\end{array}$ & $\begin{array}{l}\text { Analiza la obra de Roger } \\
\text { Bacon como la de un pensador } \\
\text { revolucionario anti-dogmático } \\
\text { medieval, víctima de la persecución } \\
\text { católica condenado a reclusión y } \\
\text { quien se le prohibió escribir }\end{array}$ & Ensayo \\
\hline Hay que leer estos libros & $\begin{array}{l}\text { Repertorio Americano, XXIV No 8, } \\
\text { (5-3-1932), p. 128 }\end{array}$ & $\begin{array}{l}\text { Recomienda leer libros sobre } \\
\text { sexualidad para romper prejuicios, } \\
\text { en especial a maestros, padres, } \\
\text { sacerdotes. Incluye investigaciones } \\
\text { de Freud. Pronostica que el } \\
\text { psicoanálisis tendrá, en medio } \\
\text { siglo, el reconocimiento a su valor. }\end{array}$ & \\
\hline \hline
\end{tabular}

\section{Corina Rodríguez López de Cornick}

\begin{tabular}{|c|c|c|c|}
\hline Título & Referencia & Temática & Género \\
\hline El hogar nacional & $\begin{array}{l}\text { Repertorio Americano, Tomo } \mathrm{V}, \mathrm{N}^{\circ} 1 \text {, } \\
(9-10-1922), \text { p. } 1-2\end{array}$ & $\begin{array}{l}\text { La necesidad de un hogar (asilo) } \\
\text { para niños que no lo tienen. La } \\
\text { niñez como objetivo de toda } \\
\text { política. La escuela ideal y los } \\
\text { educadores modernos }\end{array}$ & Ensayo \\
\hline Pastoras & $\begin{array}{l}\text { Repertorio Americano, Tomo V. N }{ }^{\circ} 13 \text {, } \\
(18-12-1922) \text { p. } 170\end{array}$ & $\begin{array}{l}\text { Navidad, religiosa, el dolor } \\
\text { emocional }\end{array}$ & Prosa poética \\
\hline $\begin{array}{l}\text { Comentando las palabras } \\
\text { del Sr. Carazo }\end{array}$ & $\begin{array}{l}\text { Repertorio Americano, Tomo } \mathrm{V}, \mathrm{N}^{\circ} 3 \\
(23-10-1923) \text { p. } 38\end{array}$ & $\begin{array}{l}\text { Una alocución de Juan José } \\
\text { Carazo sobre la condición de la } \\
\text { niñez y el proyecto de crear el } \\
\text { hogar nacional de niños }\end{array}$ & Ensayo \\
\hline $\begin{array}{l}\text { A los maestros de Costa } \\
\text { Rica }\end{array}$ & $\begin{array}{l}\text { Repertorio Americano, Tomo XV, No } 20 \\
(26-11-1927) \text { p. } 311\end{array}$ & $\begin{array}{l}\text { Crítica a las doctrinas del } \\
\text { panamericanismo y del } \\
\text { hispanoamericanismo. El } \\
\text { enriquecimiento de los oligarcas } \\
\text { de Norte y Suramérica con } \\
\text { el negocio de la guerra y el } \\
\text { desempleo rampante }\end{array}$ & Ensayo \\
\hline De la entraña & $\begin{array}{l}\text { Repertorio Americano, XVII, N } 11 \\
(15-9-1928), \text { p. } 174\end{array}$ & $\begin{array}{l}\text { La maternidad como } \\
\text { responsabilidad. La necesaria } \\
\text { guía de los hijos }\end{array}$ & $\begin{array}{l}\text { Prosa poética. } \\
\text { Reseña de su } \\
\text { libro por Carmen } \\
\text { Lyra }\end{array}$ \\
\hline
\end{tabular}




\section{URL: http://www.una.ac.cr/educare}

\begin{tabular}{|l|l|l|l|}
\hline Título & Referencia & Temática & Género \\
\hline Max Jiménez & $\begin{array}{l}\text { Repertorio Americano, XLVIII, N }{ }^{\circ} 1 \\
(1947) \text { pp. 7-8 }\end{array}$ & $\begin{array}{l}\text { Semblanza de Max Jiménez, } \\
\text { artista comprometido con la } \\
\text { justicia social, soslayado por el } \\
\text { espíritu conservador costarricense }\end{array}$ & Ensayo \\
\hline $\begin{array}{l}\text { Mercedes Arce y la } \\
\text { gimnasia }\end{array}$ & $\begin{array}{l}\text { Repertorio Americano, XLIV, N }{ }^{\circ} \text { 22, } \\
(12-12-1949) \text { p. 350 }\end{array}$ & $\begin{array}{l}\text { Semblanza de esta maestra de la } \\
\text { gimnasia y su método de enseñanza }\end{array}$ & Ensayo \\
\hline Arcadia tropical & $\begin{array}{l}\text { Repertorio Americano, XKV, N } \text { N }^{\circ} 2 \\
(10-12-1949) \text { pp. 373-375 }\end{array}$ & $\begin{array}{l}\text { La isla Barro Colorado, un santuario } \\
\text { silvestre, centro de investigación } \\
\text { científica sobre su flora y fauna. }\end{array}$ & Ensayo \\
\hline
\end{tabular}

Adela Ferrero de Sáenz

\begin{tabular}{|c|c|c|c|}
\hline Título & Referencia & Temática & Género literario \\
\hline $\begin{array}{l}\text { Cinco días a través de la } \\
\text { Turingia }\end{array}$ & $\begin{array}{l}\text { Repertorio Americano, XLIX, N }{ }^{\circ} 14 \\
(4-5-1957) \text { pp. } 218 \text { a } 219\end{array}$ & $\begin{array}{l}\text { Visita a la República Democrática } \\
\text { Alemana por invitación de la } \\
\text { Unión Democrática de Mujeres y } \\
\text { el recorrido que lleva a la escritora } \\
\text { al encuentro de la historia y de la } \\
\text { vivencia cotidiana del socialismo en } \\
\text { las cooperativas: la belleza de las } \\
\text { escuelas, las casas de los maestros, la } \\
\text { dignidad en las condiciones de vida } \\
\text { de los campesinos }\end{array}$ & Crónica \\
\hline
\end{tabular}

Esther de Mezerville

\begin{tabular}{|l|l|l|l|}
\hline Título & Referencia & Temática & Género literario \\
\hline \hline Palabras rectorales & $\begin{array}{l}\text { Repertorio Americano, XI, No } 16 \\
(28-12-1925) \text { pp. 256 a 258 }\end{array}$ & $\begin{array}{l}\text { Con el cierre de curso del CSU, } \\
\text { analiza cómo se ha realizado } \\
\text { la tarea educativa y cómo } \\
\text { pueden influir las educandas } \\
\text { en el mejoramiento cultural y } \\
\text { científico costarricense }\end{array}$ & Ensayo \\
& & \\
\hline
\end{tabular}

Ana Rosa Chacón

\begin{tabular}{|l|l|l|l|}
\hline Título & Referencia & Temática & Género literario \\
\hline Mencha González & $\begin{array}{l}\text { Repertorio Americano, XI, No 11 } \\
(23-11-1925) \text { pp. 169-170 }\end{array}$ & $\begin{array}{l}\text { Semblanza de la bailarina } \\
\text { Clemencia González muerte }\end{array}$ & Semblanza \\
\hline
\end{tabular}

Marta Dittel

\begin{tabular}{|l|l|l|l|}
\hline Título & Referencia & Temática & Género literario \\
\hline Palabras & $\begin{array}{l}\text { Repertorio Americano, XI, N }{ }^{\circ} 14 \\
(14-12-1925) \text { p. } 215\end{array}$ & $\begin{array}{l}\text { Discurso en la Asamblea de } \\
\text { Graduados de la Escuela Normal } \\
\text { en alabanza del Alma Mater y de } \\
\text { los maestros que sembraron el } \\
\text { ideal de justicia y educación }\end{array}$ & Discurso \\
\hline
\end{tabular}

Nota: Elaboración propia. 


\section{A manera de conclusión}

El ejercicio del derecho ciudadano de participar de lo público hizo que las maestras buscaran influir en pro de mejoras para la niñez y las mujeres, abogaran por reivindicaciones de justicia social para los grupos de artesanos y obreros, denunciaran los acuerdos partidarios que incidían en las políticas educativas y en destituciones laborales, entre otros.

Con la recopilación de escritos de las maestras costarricenses, se puede observar en los temas que ellas tratan, que estaban conscientes de la doble dimensión de la escuela, en lo social y lo político. Su discurso cívico se relacionaba indefectiblemente con la protección a la infancia, en cifrar en la educación el fundamento de la verdadera cultura cívica y política del país y de un planteamiento humanístico del ejercicio magisterial que promoviera, en los educandos, la trascendencia espiritual. Los otros discursos, el literario incluido, conllevan siempre una enseñanza, una moraleja y una intención perlocutiva política: mover a conciencia al lector.

Sin embargo, lejos de lo que tradicionalmente se quiere hacer creer, las maestras históricamente demostraron una gran conciencia de su papel social, lo cual las movió a continuar expresándose en la prensa. Su denuncia no se quedan en los efectos de la injusticia social que ven día a día, en la hora del recreo, en sus alumnas más pobres; en la debilidad de los niños por falta de alimentación adecuada o en el trabajo infantil bajo condiciones de explotación, el cual muchos pequeños se veían obligados a realizar para ayudar a la mísera economía familiar, sino que buscaron e identificaron las causas de estas condiciones.

La injusticia social que denunciaron las maestras de la primera mitad del siglo $\mathrm{XX}$ en Repertorio Americano versa sobre la explotación obrera, el abandono infantil y femenino, la irresponsabilidad de los varones de no velar por sus familias, el desinterés del Estado por proteger a la población más vulnerable y basarse solo en prácticas de beneficiencia pública que, aunque necesaria, era solo un paliativo de las adversas condiciones de grandes contingentes sociales. A nivel nacional e internacional, también denunciaron el acecho sobre las riquezas del país, el interés de mercantilización de los servicios públicos fundamentales, como la electricidad, por parte de las élites políticas y económicas; los negocios con los bienes públicos que hacían oscuros personajes en el poder, en beneficio propio, y con posiciones abiertamente antiimperialistas, de la venta de la Patria al capital extranjero y de la falta de compromiso patriótico de quienes ostentan puestos públicos. Ellas responsabilizaron al capitalismo, a la burguesía, al imperialismo y a los políticos...

Con base en lo anterior, no es arriesgado decir que las maestras que escribieron en el Repertorio Americano, desde sus propias trincheras y referentes de conocimiento, elaboraron discursos para cuestionar lo que se consideraba cívico y patriótico, y propusieron un acercamiento a estos términos enraizado con la cotidianidad. La vivencia de lo cívico lo entendieron como el logro de esa justicia social a la que los maestros y maestras, los intelectuales, pero también los obreros y campesinos, estaban llamados a conseguir de la res pública.

Las maestras cuestionaron una formación donde se instruye a los niños a ser ciudadanos a partir de la enseñanza de la organización política del país, de cómo funcionan y cuáles son los alcances de las secretarías de gobierno y de cuáles son los deberes que como ciudadanos les corresponde cumplir; pero donde se obviaba, también como valor cívico, criticar la pobreza, denunciar la injusticia, la división social. Reclamaron, para ello, la falta de medios 
para la educación como única opción viable para el mejoramiento social del individuo y del país, y la postergación en que estaba sometida la mujer. Estos aspectos, en los escritos de las mujeres del magisterio, eran los elementos que deberían analizarse como instrucción cívica, para la construcción de ciudadanía y el patriotismo.

En un momento histórico, cuando la responsabilidad materna transcendió de lo privado del hogar para convertirse en tarea cívica y de significado social en la construcción de ciudadanía como fundamento patriótico, la función de la maestra cobró importancia. Ellas crearon, en las páginas del Repertorio Americano, una conciencia cívica cuestionadora. No llamaron abiertamente a una rebelión, pero declararon que el ideal cívico se entendía a partir de reflexionar, de cuestionar y de cambiar lo que era necesario para tener una Patria más justa.

\section{Referencias bibliográficas}

Ballesteros, L. (1997). La escritora en la sociedad latinoamericana. Colombia: Editorial Universidad del Valle.

Brenes, M. (2004). Una lectura feminista de Repertorio Americano (Tesis de Maestría). Maestría Regional en Estudios de la Mujer. Heredia, Universidad Nacional de Costa Rica.

Devés, E. (2007). Redes intelectuales en América Latina. Hacia la constitución de una comunidad intelectual (Colección Idea). Chile: Instituto de estudios avanzados.

Gallardo, F. (2004). Las ideas feministas latinoamericanas. Colombia: Ediciones desde Abajo.

García, J. (Editor). (1919-1958). Repertorio Americano. Costa Rica: Alsina/Borrasé.

González, L. F. (1979). Evolución de la instrucción pública en Costa Rica. San José, Costa Rica: Editorial Costa Rica.

Jiménez, R. (1926). Instrucción cívica. Para uso de las escuelas de Costa Rica. San José, Costa Rica: Imprenta María V. de Lines.

Molina, I. y Palmer, S. (2003). Educando a Costa Rica. Alfabetización popular, formación docente y género (1880-1950). Costa Rica: EUNED

Palacios, M. (2006). La enseñanza de la instrucción cívica costarricense: Un acercamiento desde el contenido de los programas educativos en el período: 1886-1920. Revista Actualidades Investigativas en Educación, 6(3), 1-30. Recuperado de http://revista.inie.ucr.ac.cr/uploads/ $\underline{\text { tx magazine/civi.pdf }}$ 
URL: http://www.una.ac.cr/educare

Prada, G. (2001). Las maestras "Rudecindas”. Ensayos pedagógicos, 1, 53-62.

Sarmiento, D. F. (1939). Juicios de Sarmiento sobre la mujer: 1888-1938. Buenos Aires: Ministerio de Justicia e Instrucción Pública

Weinberg, L. (2004). Max Bense. Sobre el ensayo y su prosa. México: Centro Coordinador y Difusor de Estudios Latinoamericanos-UNAM. 